\title{
Anesthetized Lethal Injection Euthanasia
}

National Cancer Institute

\section{Source}

National Cancer Institute. Anesthetized Lethal Injection Euthanasia. NCI Thesaurus. Code C116217.

A method of euthanasia whereby a subject is anesthetized and a lethal chemical is administered by injection to induce death. 